\title{
Segurança Alimentar e Produção de Etanol no Brasil
}

\author{
Rodolfo Hoffmann ${ }^{1}$
}

O Brasil possui vantagens comparativas para a produção de etanol e deverá aproveitá-las, promovendo 0 crescimento econômico e contribuindo para o menor uso de combustíveis fósseis. É necessário cuidado com os aspectos ambientais e os impactos socioeconômicos do crescimento da produção de etanol, mas seus efeitos sobre a segurança alimentar no país deverão ser predominantemente benéficos. A insegurança alimentar no Brasil está fortemente associada à pobreza, que deverá ser reduzida com o aumento do emprego e da renda decorrentes do crescimento da agroindústria canavieira, superando os efeitos negativos associados a eventuais aumentos de preços de alimentos.

Palavras-chave: segurança alimentar, etanol, Brasil

\section{Food Security and Ethanol Production in Brazil}

Brazil has comparative advantages in the production of ethanol and shall use them, promoting economic growth and contributing to a reduction in fossil fuel utilization. Environmental aspects and the socio-economic impact of the increase in ethanol production have to be taken into account, but the effects of increased ethanol production on the country's food security will be mainly positive. Lack of food security in Brazil is strongly associated with poverty, which should diminish with the increases in employment and income that will come from the expansion of sugar cane agribusiness, thus compensating the negative effects of eventual food prices increases.

Keywords: food security, ethanol, Brazil

\footnotetext{
${ }^{1}$ Instituto de Economia - IE (UNICAMP)
} 
O Brasil é o único país do mundo onde uma grande parte do combustível consumido pelos automóveis é renovável e a maioria dos novos automóveis produzidos pode usar esse combustível renovável: 0 etanol.

Enquanto no Brasil o etanol é produzido a partir da cultura da cana-de-açúcar, os EUA produzem um volume semelhante de etanol a partir do amido do milho, um procedimento que é reconhecidamente menos eficiente em termos de balanço energético e econômico. A produção americana depende de substanciais subsídios governamentais. ${ }^{2}$

O Brasil tem notórias vantagens comparativas para a produção de etanol. Em uma análise ponderada afirma-se que "o Brasil foi privilegiado pela natureza e pode contribuir com a redução da poluição mundial, fornecendo o melhor combustível para veículos leves já idealizado pelo homem e, ainda assim, obter um excelente lucro" [1].

Em artigo com grande repercussão, os economistas Runge e Senauer criticam o programa americano de produção de etanol, especialmente seus efeitos perversos sobre a segurança alimentar no mundo. "Encher o tanque de um utilitário esportivo (95 litros) com etanol puro exigiria mais de 200 quilos de milho, um volume de cereal que contém calorias suficientes para alimentar uma pessoa por um ano. Ao pressionar a oferta mundial de safras comestíveis, a alta na produção de etanol se traduzirá em preços mais elevados tanto para os alimentos industrializados quanto para os básicos, em todo 0 mundo. O s biocombustíveis terminaram por amarrar os preços da comida e os do petróleo de uma maneira que pode perturbar, profundamente, 0 relacionamento entre produtores e consumidores de alimentos, e entre as nações, nos próximos anos, 0 que acarreta implicações potencialmente devastadoras tanto para a pobreza no mundo quanto para a segurança alimentar" [2].

\section{O crescimento "artificial” da demanda por um}

produto agrícola pode causar fome? Sim, pode. Amartya Sen [3], no capítulo 6 do seu livro sobre Poverty and famines, mostra como grandes aumentos no preço do arroz, causados por gastos militares, combinados com a formação de estoques especulativos do cereal, ${ }^{3}$ fizeram com que este alimento básico se tornasse inacessível aos mais pobres, matando de fome 1,5 milhão de pessoas na região de Bengala, na Índia, em 1943.

D esnecessário dizer que Runge e Senauer não consideram a possibilidade de 0 crescimento do preço do milho causar uma famine nos Estados Unidos. Mas eles mostram como o crescimento do preço do milho nos Estados Unidos contribuiu para um aumento drástico no preço da farinha para tortillas no México. "A disparada nos preços foi exacerbada por manobras especulativas e por formação de estoques. Com cerca de metade dos cerca de 107 milhões de habitantes do México vivendo na pobreza e dependendo das tortillas como fonte principal de calorias, os protestos públicos foram ferozes. Em janeiro de 2007, Felipe Calderón, o novo presidente do México, foi forçado a impor limites de preços aos derivados de milho" [2].

Runge e Senauer também assinalam que 0 lobby do etanol de milho nos Estados Unidos leva à imposição de tarifas elevadas que impedem 0 crescimento das importações de etanol do Brasil, onde a produção é mais eficiente, dificultando 0 crescimento econômico ea criação de empregos aqui. Oxalá tivessem, México e Brasil, mais poder de lobby na determinação da política econômica dos Estados Unidos.

Passemos a focalizar nossa atenção nas possíveis conseqüências do rápido crescimento da produção de etanol no Brasil. Este crescimento terá efeitos no preço de alimentos? É óbvio que sim, devido à competição no uso dos recursos.

Argumenta-se que há terras ociosas ou subaproveitadas que podem ser utilizadas para expandir a lavoura da cana-de-açúcar, sem

\footnotetext{
${ }^{2} \mathrm{O}$ subsídio à produção de álcool de milho nos EUA é um caso conhecido de ingerência de um poderoso lobby na formulação da política econômica. Em livro sobre teoria econômica, o caso é citado como exemplo a ser evitado [4].

${ }^{3}$ Cabe acrescentar a ineficácia da intervenção governamental, sempre baseada em um diagnóstico errôneo que admitia que a causa da fome era uma redução na quantidade de arroz disponível na região.
} 
necessidade de qualquer desmatamento. "A Embrapa estima haver cerca de 90 milhões de hectares disponíveis para expansão da agricultura no Brasil, que possui um território total de 852 milhões de hectares. A atual área plantada com cana-de-açúcar é pouco superior a 6 milhões de hectares (safra 20052006), ou seja, menos de 1\% do território nacional. Ademais, mais de 30 milhões de hectares ocupados com pastagens extensivas subaproveitadas poderão ser liberados nos próximos anos para exercício de outras atividades agrícolas, sem prejuízo às produções de carne e leite, fato já constatado para o Estado de São Paulo" [5]. Mas estas terras ociosas ou subaproveitadas têm dono e é provável que haja necessidade de algum estímulo (na forma de aumento de preço), para que elas passem a ser mais bem utilizadas.

É certo que o progresso tecnológico na produção agropecuária está constantemente contribuindo para a redução do preço dos alimentos. Assim, dependendo do ritmo do crescimento da produção de etanol, o seu efeito sobre o preço de alguns alimentos pode se manifestar apenas como ausência de redução ou redução menor.

É importante ter em mente que o crescimento da produção de etanol representa crescimento econômico com geração de novos empregos e mais renda.

A economia não é um jogo de soma igual a zero, isto é, quando alguns ganham não é necessário que outros estejam perdendo. 0 desenvolvimento econômico pode gerar benefícios para todos. É verdade, entretanto, que dificilmente 0 crescimento econômico beneficia a todos igualmente, sendo comum que alguns sejam prejudicados. $\mathrm{O}$ fenômeno pode ser ilustrado pela seguinte notícia ${ }^{4}$ :

Cana invade áreas tradicionalmente ocupadas pelo boi.

O treminhão corta a estrada poeirenta sem muita sutileza. Um a cada três minutos. Enquanto isso, o gado confinado pastoreia na braquiária empoeirada. Os trens de estrada repletos de cana correm para alimentar as famintas moendas da novíssima Usina Continental, em Colômbia, região de Barretos, a ex-Meca do boi, a 425 quilômetros de São Paulo. É para lá que ainda caminham, todo mês de agosto, multidões de peões de imitação atrás do maior rodeio do Brasil, o Barretão. Mas peão de verdade -- que acorda às 4 da manhã para a lida da vacada -- escasseia por essas bandas. O etanol de Lula e de Bush está numa velocidade impressionante, expulsando a tradicional pecuária comercial de São Paulo e mudando a vida de muita gente.

Mesmo sendo provável que haja substanciais benefícios líquidos como resultado da expansão da produção de etanol no Brasil, é necessário estar atento para os grupos prejudicados e promover políticas compensatórias. É consensual, por exemplo, que o estado, em cooperação com as empresas, deva ter programas de treinamento e realocação das pessoas desempregadas, devido à mecanização da colheita da cana-de-açúcar.

D esnecessário dizer que é fundamental monitorar e regulamentar os aspectos ambientais, como bem discutem Strapasson e Job [5].

No Brasil, é a pobreza que causa insegurança alimentar. A quantidade de alimentos produzida supera com folga as necessidades de sustento da população do país. D ados da Pesquisa Nacional por Amostra de Domicílios (PNAD) de 2004 mostram que $6,5 \%$ dos domicílios (com 7,7\% das pessoas) sofrem de insegurança alimentar grave, fortemente associada ao baixíssimo valor do rendimento destas pessoas [6]. A expansão da produção de etanol vai propiciar aumentos de emprego e renda, que irão contribuir para reduzir a pobreza e a insegurança alimentar, e é improvável que eventuais aumentos de preços de alimentos tenham efeitos que cheguem a anular ou superar estes efeitos benéficos do crescimento econômico, associado à expansão da agroindústria canavieira.

De acordo com dados da Pesquisa de

\footnotetext{
${ }^{4}$ D o "Correio do Estado", reproduzido no A grolink de 16 de abril de 2007.
} 
O rçamentos Familiares de 2002-2003, 30\% das famílias tinham pelo menos um automóvel. Esta proporção era apenas 4,6\% nas famílias com renda per capita até $\mathrm{R} \$$ 100 e atingia 79,0\% para as famílias com renda per capita acima de R 4.000 (em reais de janeiro de 2003). No apêndice, mostra-se que a despesa com combustíveis de carros de passeio é uma característica dos relativamente ricos. A concentração destas despesas em uma parcela pequena das famílias é, obviamente, um reflexo da elevada desigualdade da distribuição de renda no Brasil. Mas seria um absurdo pensar em combater a desigualdade elevada impedindo a produção de bens "de luxo" 5 . Com o crescimento econômico, necessariamente aumentará, de modo mais rápido, a demanda dos produtos com maior elasticidade-renda. A produção nacional de etanol deverá crescer para atender a demanda interna e também para 0 país aproveitar suas vantagens comparativas no mercado mundial. Isto deverá ser feito com o devido cuidado no que se refere ao meio ambiente, aperfeiçoando a legislação e tornando mais rigorosa a respectiva fiscalização. Como exemplos, cabe mencionar a necessidade de combater, com mais rigor, a poluição causada pela queima dos canaviais e, no processo de expansão daárea cultivada, preservar e restauraras matas ciliares.

\section{Apêndice: Despesas com alimentos e com combustíveis de veículos próprios, conforme estratos de renda familiar per capita.}

O objetivo deste apêndice é utilizar os dados da Pesquisa de O rçamentos Familiares (POF) de 2002-2003 para mostrar como as despesas com gasolina e álcool, para veículo próprio, estão concentradas entre os relativamente ricos, em particular quando utilizamos a despesa com alimentação como base de comparação.

A população do país foi dividida em 10 estratos de renda familiar per capita. 0 estrato mais pobre, incluindo aqueles cuja renda mensal per capita não excede R\$ 100 (de janeiro de 2003), fica com 19,0\% da população. O estrato mais rico, com renda per capita acima de $\mathrm{R} \$ 4.000$, fica com 1,1\% da população.

A tabela 1 mostra que, enquanto no estrato mais pobre a despesa com transporte representa cerca de 1/ 4 da despesa com alimentação, no estrato mais rico a despesa com transporte supera o dobro da despesa com alimentação. No estrato mais pobre a despesa com combustível para veículo próprio é irrisória, ao passo que no estrato mais rico esta despesa corresponde a quase metade da despesa com alimentação.

Tabela 1. D espesas mensais per capita com alimentação e com combustíveis para veículos próprios por estrato de renda familiar per capita, no Brasil, em 2002-2003.

\begin{tabular}{|c|c|c|c|c|c|c|c|c|}
\hline \multirow{2}{*}{$\begin{array}{c}\text { Estrato de renda } \\
\text { familiar per capita } \\
\text { (R\$)(1) }\end{array}$} & \multicolumn{2}{|c|}{ Pessoas } & \multicolumn{4}{|c|}{ Despesa mensal per capita $(\mathbf{R} \$)^{(1)}$} & \multicolumn{2}{|c|}{ Famílias } \\
\hline & $\begin{array}{c}\text { No } \\
\text { (mil) }\end{array}$ & $\%$ & $\begin{array}{l}\text { Alimen- } \\
\text { tação(2) }\end{array}$ & Transporte & $\begin{array}{l}\text { Gasolina } \\
\text { e álcool(3) }\end{array}$ & Consumo(4) & $\begin{array}{c}\text { No } \\
\text { (mil) }\end{array}$ & $\begin{array}{c}\% \text { com } \\
\text { automóvel }\end{array}$ \\
\hline 0 a 100 & 33.476 & 19,0 & 37,9 & 9,2 & 1,1 & 99,8 & 6.495 & 4,6 \\
\hline Mais de 100 a 200 & 39.377 & 22,4 & 54,1 & 18,8 & 2,6 & 173,0 & 9.419 & 10,5 \\
\hline Mais de 200 a 400 & 45.038 & 25,6 & 75,7 & 40,4 & 8,1 & 290,6 & 13.015 & 21,5 \\
\hline Mais de 400 a 600 & 20.526 & 11,7 & 96,4 & 77,5 & 17,1 & 448,0 & 6.520 & 36,1 \\
\hline Mais de 600 a 800 & 11.286 & 6,4 & 115,7 & 116,1 & 28,5 & 596,3 & 3.679 & 49,6 \\
\hline Mais de 800 a 1000 & 6.584 & 3,7 & 123,3 & 145,7 & 32,3 & 706,1 & 2.215 & 53,9 \\
\hline Mais de 1000 a 1500 & 8.584 & 4,9 & 148,0 & 215,9 & 49,3 & 941,2 & 2.919 & 65,7 \\
\hline Mais de 1500 a 2500 & 6.469 & 3,7 & 193,0 & 303,4 & 73,0 & $1.329,0$ & 2.307 & 72,1 \\
\hline Mais de 2500 a 4000 & 2.652 & 1,5 & 251,8 & 446,4 & 93,0 & $1.915,3$ & 1.088 & 77,4 \\
\hline Mais de 4000 & 1.854 & 1,1 & 359,2 & 747,6 & 156,3 & $2.989,0$ & 877 & 79,0 \\
\hline Total & 175.846 & 100,0 & 83,9 & 74,6 & 16,0 & 404,4 & 48.535 & 30,0 \\
\hline
\end{tabular}

Fonte: Microdados da POF de 2002-2003, IBGE.

(1) Em reais de janeiro de 2003.

(2) Inclui alimentação fora do domicílio.

(3) Usados como combustíveis de veículos próprios. É parte das despesas de transporte.

(4) D espesa total com consumo.

${ }^{5}$ Para uma análise recente da desigualdade da distribuição da renda no Brasil e das maneiras de combatê-la, ver Barros et al [7]. 
Utilizando os microdados da POF, pode-se verificar que os dois primeiros estratos, com renda per capita igual ou menor do que $\mathrm{R} \$ 200$, que incluem $41,4 \%$ das pessoas, ficam com $9,0 \%$ da renda total, 23,0\% da despesa total com alimentação, 8,0\% da despesa com transporte e apenas 4,8\% da despesa com gasolina e álcool. Por outro lado, os três estratos mais ricos, com renda per capita acima de $\mathrm{R} \$ 1.500$, que incluem $6,2 \%$ das pessoas, ficam com $37,7 \%$ da renda total, $17,5 \%$ da despesa com alimentação, 34,6\% da despesa com transporte e 35,8\% da despesa com gasolina e álcool.

Uma outra maneira de contrastar o comportamento de diversos tipos de despesas é considerar a sua elasticidade-renda, que indica em quanto tende a aumentar, percentualmente, a despesa, quando a renda familiar per capita aumenta em $1 \%$. Estimamos que a elasticidade-renda média, no Brasil, é 0,381 para alimentação no domicílio, 0,481 para todas as despesas com alimentação e 0,966 para despesas com transporte [8]. Utilizando a mesma metodologia, a elasticidade-renda das despesas com gasolina e álcool, para veículo próprio, é 1,047.

\section{Referências Bibliográficas}

[1] Morceli, P. (2006) Futuro para o álcool brasileiro. Revista de Política A gríolla 15 (3): 19-27, jul.-set. 2006.

[2] Runge, C. F.; Senauer, B. (2007) A bolha do etanol. Artigo da "Foreign Affairs" disponibilizado pela
"Folha on line", acessado em 05/ 04/ 2007.

[3] Sen, A. (1981) Poverty and famines: an essay on entitlement and deprivation. Oxford University Press.

[4] Beinhocker, E. D. (2006) The origin of wealth: evolution, omplex ity and the radical remaking of economics. Harvard Business School Press.

[5] Strapasson, A. B. e Job, L. C. M. A. (2006) Etanol, meio ambiente e tecnologia: reflexões sobre a experiência brasileira. Revista de Política A gríola 15 (3): 51-63, jul.-set. 2006.

[6] Hoffmann, R. (2006) D eterminantes da insegurança alimentar no Brasil em 2004. X IV Congresso L atino-A mericano de N utrição. SLAN. Florianópolis, 12 a 16 de novembro de 2006.

[7] Barros, R.P.; Foguel, M.N. e Ulyssea, G. (org.)(2006) D esigualdade de renda no Brasil: uma análise da queda recente. Brasília, IPEA.

[8] Hoffmann, R. (2006) Elasticidade-renda das despesas e do consumo de alimentos no Brasil em 2002-2003. Cap. 6 do vol. II de Silveira, F. G. et al. (org.) $\mathrm{G}$ asto e consumo das famílias brasileiras contemporâneas. Brasília, IPEA.

\section{Autor}

Rodolfo Hoffmann - Professor do Instituto de Economia - IE (UNICAMP), com apoio do CNPq

Correspondência: Caixa Postal 6135, CEP 13083-857 Campinas, SP. E-mail: rhoffman@ eco.unicamp.br 